\title{
Ionic Liquid Surface Composition Controls the Size of Gold Nanoparticles Prepared by Sputtering Deposition
}

\author{
Heberton Wender, ${ }^{\dagger}$ Luciane F. de Oliveira, ${ }^{\ddagger}$ Pedro Migowski,,${ }^{\ddagger}$ Adriano F. Feil,${ }^{\dagger}$ Elizeo Lissner, ${ }^{\ddagger}$ \\ Martin H. G. Prechtl, ${ }^{\dagger}$ Sergio R. Teixeira, ${ }^{\dagger}$ and Jairton Dupont ${ }^{\ddagger} *$ \\ Laboratory of Thin Films and Nanostructures Fabrication (L3Fnano), Institute of Physics, Bento Gonçalves \\ Avenue 9500, P.O. Box 15051, 91501-970, UFRGS, Porto Alegre, Brazil and Laboratory of Molecular \\ Catalysis, Institute of Chemistry, Bento Gonçalves Avenue 9500, P.O. Box 15003, 91501-970, UFRGS, \\ Porto Alegre, RS, Brazil
}

Received: March 11, 2010; Revised Manuscript Received: May 3, 2010

\begin{abstract}
The sputtering of gold foil onto 1-n-butyl-3-methylimidazolium tetrafluoroborate, hexafluorophosphate, bis(trifluoromethylsulfonyl)amide, or tris(fluoro)tris(perfluoroethane)phosphate ionic liquids (ILs) generates stable and well-dispersed gold nanoparticles (NPs) of 3-5 nm under conditions of $40 \mathrm{~mA}, 335 \mathrm{~V}$, and $2 \mathrm{~Pa}$ Ar work pressure. The size and size distribution of these Au nanoparticles depends on various experimental parameters, particularly the surface composition of the IL and less so the surface tension and viscosity. Under the experimental conditions used here, both nucleation and NP growth seem to occur on the IL surface and the NP size changes with the changes in the IL surface composition, especially with the increase of the fluorinated content. Moreover, the NP size is independent of sputtering time but does depend on the discharge current. When higher discharge currents are used, more gold atoms hit the ionic liquid surface per unit time, changing the kinetics of particle growth on the surface of the IL.
\end{abstract}

\section{Introduction}

Ionic liquids (ILs), especially imidazolium-based ILs, have proven to be suitable media for the generation and stabilization of a plethora of soluble metal nanoparticles (NPs). ${ }^{1,2}$ Indeed, transition-metal NPs with small sizes, narrow size distributions and different shapes have been prepared in ILs by reduction of organometallic compounds with molecular hydrogen ${ }^{3,4}$ or hydrides, ${ }^{5,6}$ decomposition of transition-metal complexes in the zerovalent state, ${ }^{7-9}$ metal bombardment ${ }^{10,11}$ or simple transfer of previously prepared water- or classical organic solvent-soluble colloids onto the ILs. ${ }^{12,13}$ The structures of 1,3-dialkylimidazolium salts follow an archetypal trend, forming an extended network of cations and anions connected by hydrogen bonds ${ }^{14}$ in the condensed phase, which is also maintained to a great extent in the gas phase. ${ }^{15}$ These IL structures can adapt to or are adaptable by many species, as they provide hydrophobic or hydrophilic regions and a highly directional polarizability, which can be oriented parallel or perpendicular to the included species. ${ }^{16}$ In fact, there is a continuous tridimensional network of ionic channels (polar domains) that coexists with nonpolar domains and may form dispersed microphases or continuous phases. ${ }^{17,18}$ The segregation of polar and nonpolar domains in imidazolium-based ILs affects their solvation and their ability to interact with different species. It has been proposed recently that the nanoparticle growth process resulting from the reduction or decomposition of metal complexes is controlled by the local concentration of the precursor and consequently limited to the size and shape of the IL polar or nonpolar domains. ${ }^{19}$ In particular, a relationship has been demonstrated between the size of IL nonpolar domains calculated by molecular dynamics

* To whom correspondence should be addressed. E-mail: jairton.dupont@ ufrgs.br.

Laboratory of Thin Films and Nanostructures Fabrication (L3Fnano).

*aboratory of Molecular Catalysis. simulations and nanoparticle size measured by TEM. ${ }^{20}$ Similarly, the volume of the polar domains of in the imidazolium ILs may be controlled by changing the anion volume. Therefore, silver NPs obtained by hydrogen reduction of silver salts dissolved in ILs and those obtained, in the presence of $n$-butylimidazole, have a narrow size distributions with diameters between $2.8-26.1 \mathrm{~nm}$, and this size distribution increases linearly with the molecular volume of the IL anion. ${ }^{21}$

In the case of sputter deposition, the bombardment of a metal foil surface with energetic gaseous ions causes the physical ejection of surface atoms and/or small metal clusters. Because of the low gas pressure, it is assumed, depending on the work pressure, that there are no considerable gas-phase collisions of the sputtered species in the space between the metal foil and the IL medium. Their injection onto the IL surface and/or bulk phase could produce an atom/cluster concentration high enough to coalesce with each other and result in the formation of nanoparticles. ${ }^{11,22-25}$ Although it is difficult to know where the NPs' nucleation and particle growth occurs, it can be anticipate that (i) the nucleation starts in on the IL surface and then diffuses into the liquid phase where particle growth takes place; (ii) both processes occurs in on the IL surface; or (iii) the metal atoms and clusters could penetrate just below the liquid phase and both processes occur in the bulk IL phase (Figure 1). Regardless of the operative processes, the nanoparticle formation will be strongly dependent on the IL surface composition and the structural organization of the bulk phase. Macroscopically, both surface and bulk composition translates into a dependence on the IL surface tension and viscosity. Apparently, the surface tension influences the initial formation process of nanoparticles on the surface of an ionic liquid, and the viscosity affects the aggregation process during the dispersion of the Au particles from the surface into the liquid. ${ }^{26}$ Moreover, the energy of the traveling metal atoms/clusters may be also an important parameter because species with too much energy will penetrate 


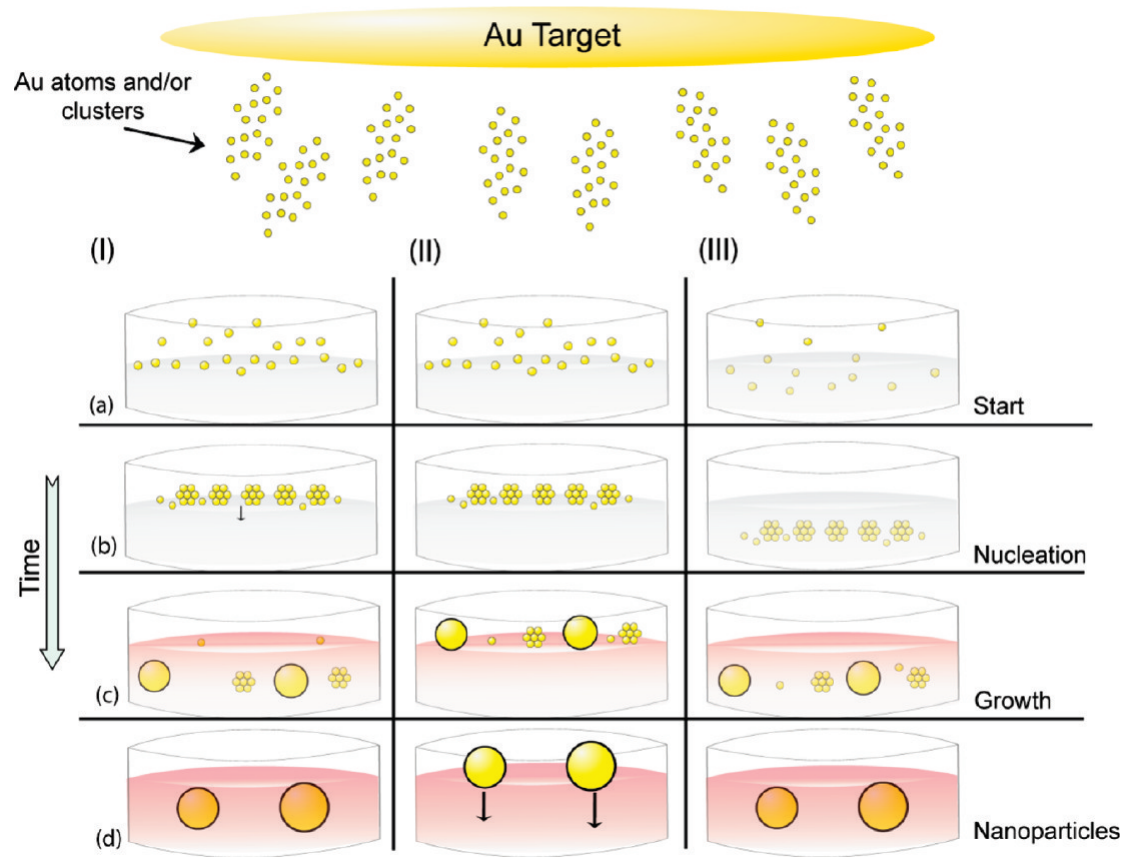

Figure 1. Possible mechanisms for the nucleation and growth of sputtered gold nanoparticles into IL substrates.

directly into the IL phase and may increase the IL temperature, consequently decreasing the surface tension and viscosity. Therefore, the nucleation step may be directly related to the surface structure and the nanoparticle growth may be related to the bulk ("inner") IL organization. Indeed, both experimental and theoretical investigations have recently found that the IL surface composition may be more or less populated with alkyl and/or fluorinated moieties depending on the type of anion and cation substituents. ${ }^{27-35}$

However, the experimental conditions (distance between the metal target and liquid surface, gas pressure, current and time, and voltage change) used thus far have varied from one study to another, making it almost impossible to compare and correlate the influence of these parameters. ${ }^{11,22-26}$ Nonetheless, it is apparent that the size of NPs depends on the type of IL and on the discharge current. For example, $5.5 \mathrm{~nm}(\sigma 0.86 \mathrm{~nm}) \mathrm{Au}$ nanoparticles were produced in $\mathrm{EMI}_{\mathrm{B}} \mathrm{BF}_{4}$, whereas sputter deposition onto $\mathrm{NMe}_{3}{ }^{n} \mathrm{Pr}$. $\mathrm{NTf}_{2}$ resulted in the formation of much smaller Au nanoparticles with sizes of $1.9 \mathrm{~nm}(\sigma 0.46 \mathrm{~nm}) .{ }^{11} \mathrm{It}$ seems as though the size of NPs can be controlled by varying the discharge current. Indeed, sputter deposition of silver onto 1-n-butyl-3-methylimidazolium hexafluorophosphate (BMI.PF $)$ produced Ag nanoparticles whose size increased from 5.7 to $11 \mathrm{~nm}$ by varying the discharge current from 10 to $40 \mathrm{~mA} .^{24}$ However, the influence of sputtering time is not yet clear. In one case, it was reported that there was no influence of the sputtering time on the size of the NPs,${ }^{11}$ whereas another study observed an increase on the size of the Au NPs with the increase of time sputtering. ${ }^{26}$

For these reasons, the issue of whether there exists a direct relation between nanoparticle size and the ionic liquid surface structure and/or bulk organization in the sputter deposition of metal nanoparticles is quite intriguing. To this end, we have investigated the sputter deposition of $\mathrm{Au}$ on various ionic liquids in which the surface and bulk composition has been modified as function of anion (Figure 2).

\section{Experimental Section}

General Considerations. All ILs used in this work were synthesized according to literature procedures, ${ }^{36,37}$ except $1-n$ -

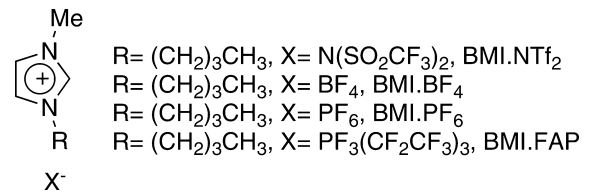

Figure 2. Structures of the ILs used in this study.

butyl-3-methylimidazolium tris(pentafluoroethyl)trifluorophosphate (BMI.FAP), which was obtained free of charge as a generous gift from Merck KgaA Germany. The ILs were dried for $3 \mathrm{~h}$ at $333 \mathrm{~K}$ under vacuum prior to use. The morphology and size distribution of $\mathrm{Au}$ NPs was examined using transmission electron microscopy (TEM) with a JEOL JEM1200 EXII operating at 80 $\mathrm{kV}$ acceleration voltages. Optical absorption spectra were measured in a Varian Cary 100 UV-visible spectrophotometer using $1 \mathrm{~mm}$ optical path quartz cuvettes.

Preparation of Gold NPs. The metal colloids were prepared by sputter deposition in imidazolium-based ionic liquids. The deposition was performed in a sputter coater MED 020 (BalTech), pre-evacuated at $10^{-3} \mathrm{~Pa}$ with discharge currents ranging from 20 to $110 \mathrm{~mA}$ ( 299 to $410 \mathrm{~V}$ ) for 150 to $600 \mathrm{~s}$, under an argon work pressure of $2.10^{\circ} \mathrm{Pa}$ at room temperature. The mass of each IL was measured (1.23 g) in a cylindrical glass support ( $3 \mathrm{~cm}$ diameter) and placed in the sputter coater horizontally. The liquid surface was located at a distance of $50 \mathrm{~mm}$ from the gold target ( $99.99 \%$ in purity). The control of deposition rate was performed in situ by a quartz crystal film thickness measurement device (QSG 060 - Bal-Tech).

TEM Sample Preparation. The TEM samples were prepared by dissolving the Au/ILs colloids in isopropanol at room temperature and then depositing them on a carbon-coated copper grid. The histograms of the nanoparticle size distribution, assuming spherical shape, were obtained from measurements of approximately 700 particles and were reproduced in arbitrarily chosen regions of a holey carbon-coated $\mathrm{Cu}$ grid.

\section{Results and Discussion}

The influence of sputtering conditions (sputtering time, discharge current,and discharge voltage) was evaluated using 

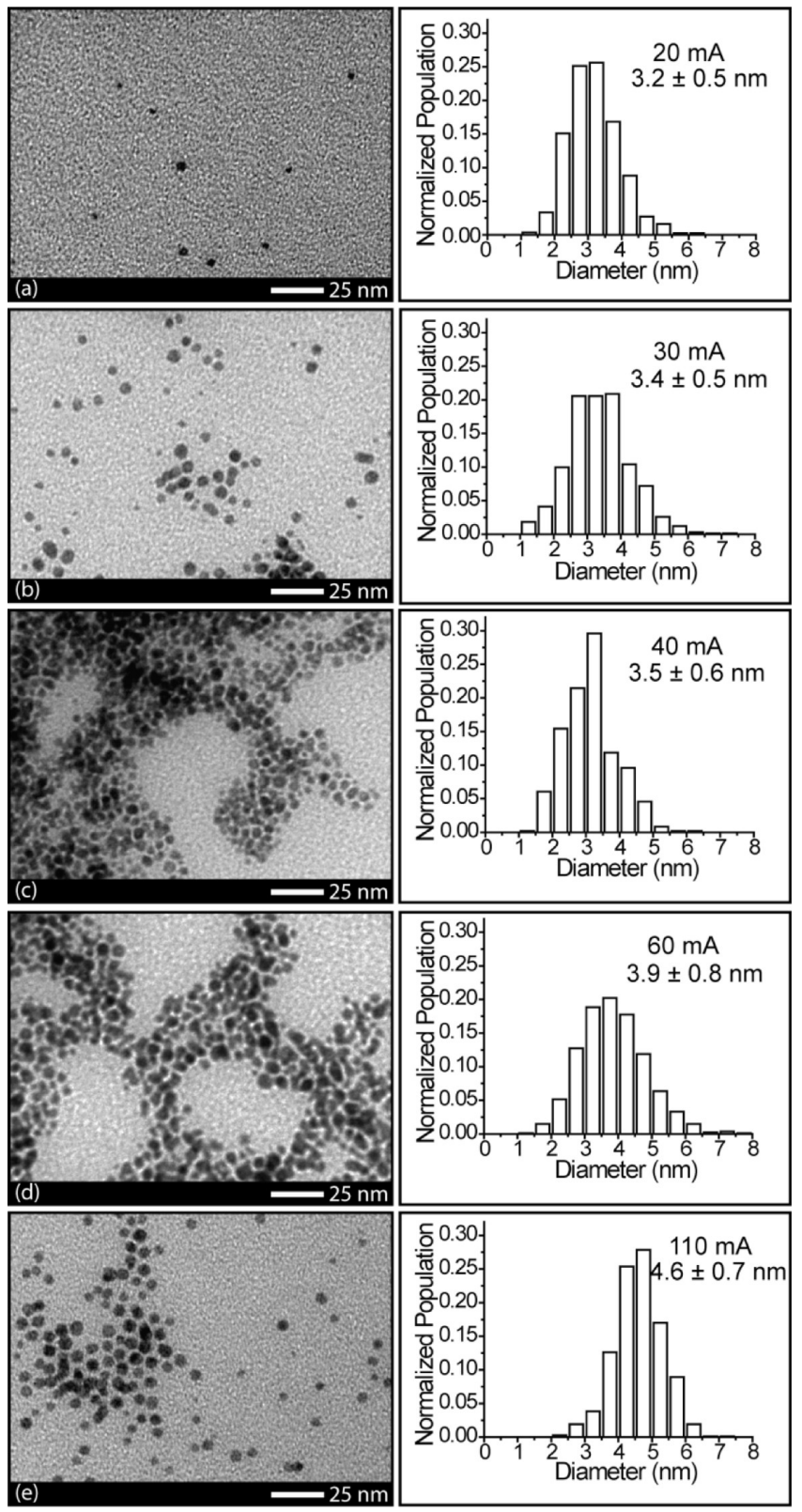

Figure 3. TEM images (left) of Au NPs sputter deposited in BMI.NTf with discharge currents of (a) 20, (b) 30, (c) 40, (d) 60, and (e) 110 $\mathrm{mA}$ and their respective histograms (right).

BMI.NTf 2 . Representative TEM images and histograms of gold nanoparticles obtained by sputter deposition of an Au target with different discharge currents are displayed in Figure 3, and the mean size versus current and time tendencies are shown in Figure 4a,b and summarized in Table 1. From the data in Figures 3 and $4 a$, it is clear that the mean diameter value of the $\mathrm{Au}$ NPs shows a tendency to increase linearly $(R=0.998)$ with discharge current increase. However, the NPs mean diameter shows no tendency to vary with deposition time at a given current. In fact, higher deposition times only increase the gold concentration in the IL, not affecting the average nanoparticle size. The UV-visible absorption spectra corroborate the results obtained from the TEM images. The absorption spectra of BMI.NTf $f_{2}$ IL after Au nanoparticle deposition with different sputtering currents and times can be seen in Figure 4 panels $\mathrm{c}$ and d, respectively. All gold colloids in BMI.NTf $\mathrm{IL}_{2}$ display a single absorption band centered near $525 \mathrm{~nm}$ due to the surface plasmon resonance (SPR) of gold nanoparticles. ${ }^{38}$ As expected,
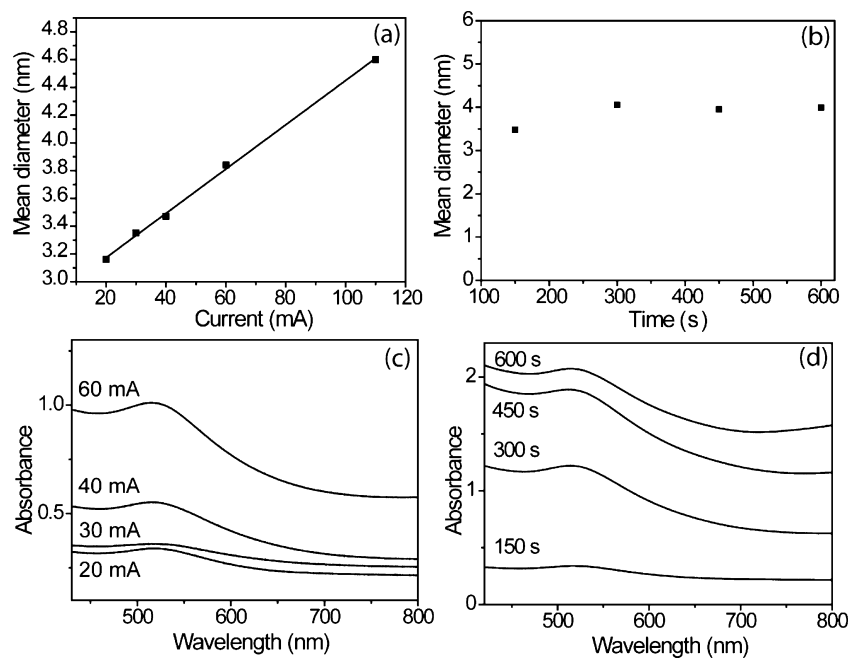

Figure 4. (a) Mean diameter of Au NPs obtained in BMI.NTf $f_{2}$ after $150 \mathrm{~s}$ of deposition in different discharge currents (b) diameter versus deposition time for Au NPs obtained in BMI.NTf ${ }_{2}$ at a fixed sputtering current of $40 \mathrm{~mA}(325 \mathrm{~V})$, (c) absorptions spectra of Au NPs in BMI.NTf $f_{2}$ obtained with different discharge currents after $150 \mathrm{~s}$ of deposition and (d) absorption spectra of Au NPs in BMI.NTf 2 at different Au sputtering times at $40 \mathrm{~mA}(325 \mathrm{~V})$.

TABLE 1: Mean Diameters (Size) and Deposition Rate of Au NPs Prepared by Sputtering in Different ILs under Various Physical Conditions (2 Pa Ar Work Pressure)

\begin{tabular}{|c|c|c|c|c|c|c|}
\hline entry & IL & $\underset{(\mathrm{mA})}{\text { current }}$ & $\begin{array}{c}\text { voltage } \\
\text { (V) }\end{array}$ & $\underset{(s)}{\text { time }}$ & $\begin{array}{l}\text { deposition } \\
\text { rate } \\
\left(\mathrm{nm} \cdot \mathrm{s}^{-1}\right)\end{array}$ & $\begin{array}{l}\text { size } \\
(\mathrm{nm})\end{array}$ \\
\hline 1 & BMI.NTf $_{2}$ & 20 & 299 & 150 & 0.20 & $3.2 \pm 0.5$ \\
\hline 2 & BMI.NTf $_{2}$ & 30 & 322 & 150 & 0.34 & $3.4 \pm 0.5$ \\
\hline 3 & BMI.NTf $_{2}$ & 40 & 335 & 150 & 0.42 & $3.5 \pm 0.6$ \\
\hline 4 & BMI.NTf $_{2}$ & 60 & 358 & 150 & 0.71 & $3.9 \pm 0.8$ \\
\hline 5 & BMI.NTf $_{2}$ & 110 & 410 & 150 & 1.65 & $4.6 \pm 0.7$ \\
\hline 6 & BMI.NTf $_{2}$ & 40 & 335 & 300 & 0.42 & $4.0 \pm 0.9$ \\
\hline 7 & BMI.NTf $_{2}$ & 40 & 335 & 450 & 0.42 & $3.9 \pm 0.8$ \\
\hline 8 & BMI.NTf $_{2}$ & 40 & 335 & 600 & 0.42 & $4.0 \pm 0.8$ \\
\hline 9 & $\mathrm{BMI} \mathrm{BF}_{4}$ & 40 & 335 & 150 & 0.42 & $3.6 \pm 0.4$ \\
\hline 10 & BMI.PF $_{6}$ & 40 & 335 & 150 & 0.42 & $3.7 \pm 0.4$ \\
\hline 11 & BMI.FAP & 40 & 335 & 150 & 0.42 & $4.9 \pm 0.9$ \\
\hline
\end{tabular}

absorbance at $525 \mathrm{~nm}$ becomes more pronounced with increasing discharge current and sputtering time, corresponding to an increase in Au NP concentration. Moreover, no displacements were observed in the SPR peaks.

These results are in agreement with those observed for the formation of Ag NPs in hydrophobic BMI.PF 6 . In the work on Ag NPs, changing the discharge current from 10 to $40 \mathrm{~mA}$ increased nanoparticle size from 5.7 to $11 \mathrm{~nm}$, though increasing sputtering time simply caused a higher concentration of nanoparticles in the IL without changing their size. ${ }^{24}$ However, our results conflict with a study on Au nanoparticles preparation in hydrophilic 1-alkyl-3-methylimidazolium tetrafluoroborate ILs, which found that the diameters of Au nanoparticles increase as a function of concentration in ILs. ${ }^{26}$

Considering that the IL BMI.NTf 2 surface composition and ion orientation were the roughly the same in all of the experiments, the observed tendency of the mean diameter with the discharge current can be directly related to the increase on the deposition rate of sputtered atoms. When higher deposition rates are used, more atoms/clusters of gold hit the surface of the ionic liquid per unit of time changing the kinetics of particle growth on the surface of the IL. The deposition time does not change the NP size because the same number of Au atoms is hitting the IL surface per unit of time. These results also strongly corroborate the assumption that under these experimental 

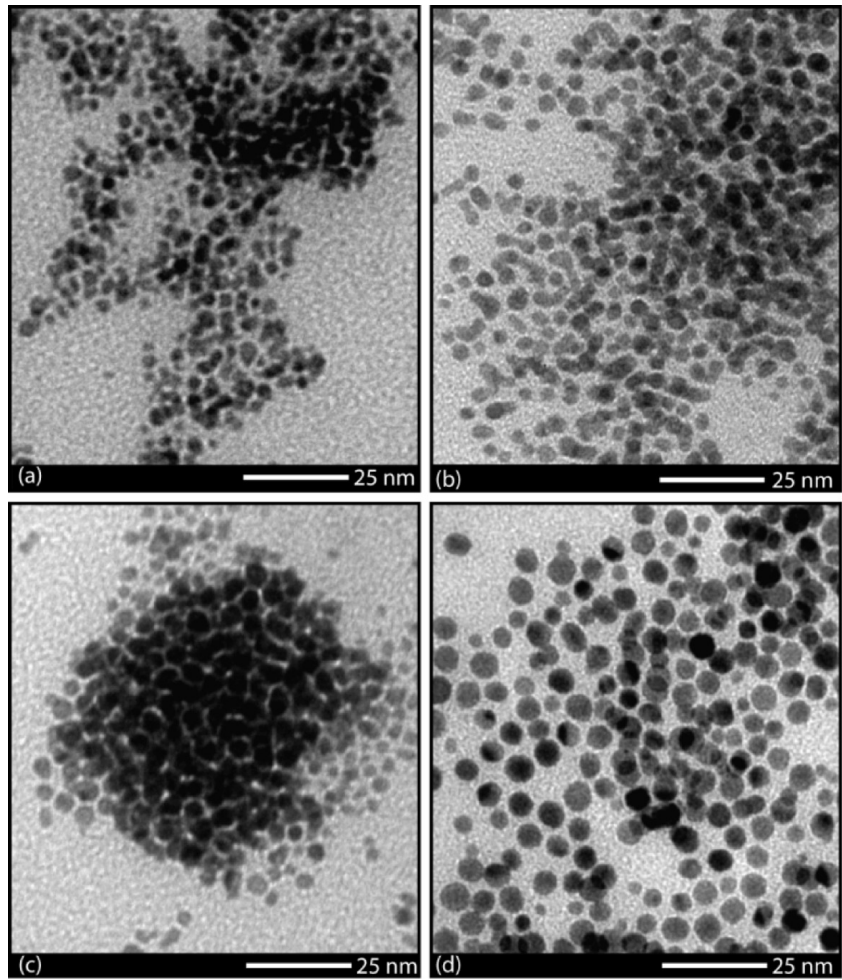

Figure 5. TEM images of Au NPs sputtered in ILs (a) BMI.NTf

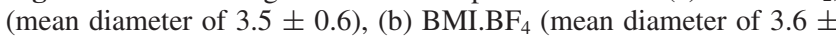
0.4 ), (c) BMI.PF 6 (mean diameter of $3.7 \pm 0.4$ ), and (d) BMI.FAP (mean diameter of $4.9 \pm 0.9$ ).

conditions used both the nucleation and the particle growth occur on the IL surface.

The influence of the IL surface composition and/or bulk organization was also investigated using Au NPs grown by sputtering a gold target with $40 \mathrm{~mA}, 325 \mathrm{~V}$ for $150 \mathrm{~s}$ with the

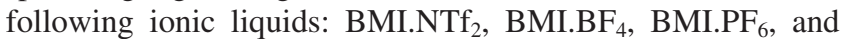
BMI.FAP. The TEM images of Au NPs are shown in Figure 5 and the mean diameter sizes are presented in Table 1.

For all anions studied, the corresponding nanoparticles possess spherical shapes with monomodal size distributions. Furthermore, the mean size $(3.6 \mathrm{~nm} \pm 0.6)$ of the NPs does not seem to be anion dependent, except in the case of the FAP anion (4.9 $\mathrm{nm} \pm 0.9)$.

The UV-vis absorption spectra of $\mathrm{Au}$ nanoparticles in different anion ILs are characterized by a single absorption peak between 520 and $530 \mathrm{~nm}$, which is attributed to SPR. Because of small changes in the average NP size, no displacement in the SPR peaks were observed.

The sizes of the Au NPs prepared in the four imidazolium ILs are not directly correlated with the surface tension or viscosity of these liquids (see Table 2). This result contradicts a recent report on the effect of different alkyl chain lengths in 1-n-alkyl-3-methylimidazolium ILs with $\mathrm{BF}_{4}$ anions on the sputtering formation of $\mathrm{Au}$ nanoparticles in which an increase in the IL surface tension was observed to increase the mean diameter of the gold nanostructures. ${ }^{26}$

These results suggest that the IL surface composition at the liquid/vacuum interface, rather than the bulk IL organization, determines the size and size distribution of Au NPs under the conditions used in this work. Indeed, if the NPs' growth occurred in the IL bulk, an increase of Au NP size with an increase of anion volume would be expected. ${ }^{21,39,40}$

IL surface organization always involves two interconnected aspects, the surface composition and the surface ion orientation.
TABLE 2: Comparison of the Physical and Chemical Properties of the ILs and the Corresponding Sizes and Size Distributions of the Au NPs Using $\mathrm{NTf}_{2}, \mathrm{PF}_{6}$, and $\mathrm{BF}_{4}$ Anions

\begin{tabular}{lcccc}
\hline $\begin{array}{c}\text { ionic } \\
\text { liquid }\end{array}$ & $\begin{array}{c}\text { viscosity } \\
\left(10^{-3} \mathrm{~Pa} \mathrm{~s}\right) \\
\text { at } 293 \mathrm{~K}\end{array}$ & $\begin{array}{c}\text { surface tension } \\
\left(10^{-3} \mathrm{~N} \cdot \mathrm{m}^{-1}\right) \text { at } 298 \mathrm{~K}\end{array}$ & $\begin{array}{c}\text { average } \\
\text { diameter } \\
(\mathrm{nm})\end{array}$ & $\begin{array}{c}\text { standard } \\
\text { deviation }\end{array}$ \\
\hline BMI.NTf $_{2}$ & 62.6 & 37.5 & 3.5 & 0.6 \\
BMI.PF $_{6}$ & 285.8 & 48.8 & 3.6 & 0.4 \\
BMI.BF $_{4}$ & 154.2 & 43.6 & 3.7 & 0.4 \\
BMI.FAP & & $33.2^{a}$ & 4.9 & 0.9
\end{tabular}

${ }^{a}$ Estimated value. ${ }^{41}$

With regard to surface composition, a consensus has been established that both cations and anions are present in the surface region of a wide range of pure imidazolium-based ILs, particularly ILs containing short alkyl chains such as 1-ethyl3-methylimidazolium. ${ }^{27,34,35}$ On the other hand, IL surfaces under vacuum that contain aliphatic alkyl chains longer than ethyl (i.e., butyl or longer) tend to be populated with nonpolar carbon chains, whereas the ionic parts of the charged imidazolium ring or the anion tend to stay in the bulk polar liquid phase. ${ }^{42-44}$ Additionally, the population of alkyl chains in the near-surface region decreases with an increase of anion size. Anions containing perfluorinated alkyl chains in particular tend to share the IL surface/vacuum interface with the alkyl side chains of imidazolium ILs. ${ }^{27,28}$ The orientation of the ionic liquid molecules on its surface must be considered. For BMI-based ILs, the imidazolium rings lie parallel to the surface plane and the butyl chain project into the gas phase, independent of anion identity. ${ }^{32}$

On the basis of the results obtained in the anion variation experiments, the IL surface composition in vacuum is apparently a key factor that controls the size of gold nanoparticles. As discussed previously, the surface composition of long side chain ILs depends on the anion. Results from angle-resolved X-ray photoelectron spectroscopy (ARXPS) studies $^{27,28}$ show that the relative concentrations of alkyl side chains and fluorinated moieties on the IL surface are $\mathrm{PF}_{6} \sim \mathrm{BF}_{4}>\mathrm{NTf}_{2} \gg$ FAP. This trend may explain the NP sizes observed in these ionic liquids. The surface compositions of $\mathrm{PF}_{6}, \mathrm{BF}_{4}$, and $\mathrm{NTf}_{2}$ ILs are very similar, yielding NPs with similar size distributions. However, when the anion tends to populate the IL surface, as in the perfluorinated alkyl side chains of FAP, the surface composition is richest in fluorinated moieties and this surface may induce the formation of larger NPs compared to those formed using other anions. It is reasonable to assume that in these cases the size of the thus formed Au NPs is probably controlled by the volume of these nonpolar surface alkyl plus perfluorinated regions where the sputtered neutral atoms/clusters tends to concentrate rather than in the regions populated by the ionic domains. These perfluorinated/alkyl domains are larger in BMI.FAP than in the other investigated ILs.

On the other case, it is known from the "bulk liquid phase" synthesis of Au nanoparticles is that the size control for metal NPs of few nanometers is achieved through electrostatic interactions of anions and the formed particle, ${ }^{4,45}$ coordination of Lewis bases (generally amines, acids, phosphines) on the surface of the particle. The extent of interaction of these stabilizing agents determines the size and shape of the particles. In the particular case of perfluorinated compounds without coordination ability, the more accepted stabilization mechanism is the crystal lattice entrapment. ${ }^{46,47}$ Looking to the system described herein and tacking into account the classical metal NPs stabilization mechanisms, it might be expected that the IL 
having more surface ions will generate NPs with lower diameters due to a higher degree of interaction between anions and particles. Moreover, it is also necessary to correlate different interactions of fully fluorinated side chains and alkyl chains and the particles, since the NPs stabilization in heavily fluorinated alkanes is attributed to particles entrapment in crystal lattice of this class of compounds. ${ }^{47}$

However, it is more likely that the observed differences are due to the chemical interactions between the sputtered atoms and the species present on the IL surface. However, disclosure about the interactions between the gold atoms that hit the surface is also a difficult task. The sputtered neutral atoms have low tendency to interact with the surface anionic species. Therefore, the results showed in our work suggest that the IL surface composition at the liquid/vacuum interface, rather than the bulk IL organization, determines the size and size distribution of $\mathrm{Au}$ NPs under the conditions used in the present work, being the surface composition an especial parameter to understand the mechanism involved.

Therefore, under the experimental conditions used in this work, the nucleation and NP growth steps might preferentially occur on the IL surface rather than in the IL and it is directly related to the IL surface composition.

\section{Conclusions}

The sizes and size distributions of Au nanoparticles prepared by sputtering of metal target with ionic liquids depend on various experimental parameters, on the IL structural organization and in particular on the surface composition, but not on surface tension or viscosity. We have demonstrated that under the physical conditions applied herein $(40 \mathrm{~mA}, 335 \mathrm{~V}$, and $2 \mathrm{~Pa} \mathrm{Ar}$ work pressure) the sizes and size distributions are independent of the sputtering time. In addition, the mean diameter of the resultant $\mathrm{Au}$ NPs shows a slight tendency to increase with the discharge current increase. When higher discharge currents are used, more gold atoms hit the ionic liquid surface per unit of time, which changes the kinetics of particle growth on the IL surface. Thus both nucleation and NP growth occur on the IL surface under these experimental conditions. Moreover, changing the IL surface composition by increasing the concentration of fluorinated moieties changes the nanoparticle growth rate and the NP sizes considerably.

Acknowledgment. Thanks are due to the following Brazilian agencies for financial support: CNPq, FAPERGS, MCT, CAPES, INCT-Catal., and CME-UFRGS.

\section{References and Notes}

(1) Migowski, P.; Dupont, J. Chem.-Eur. J. 2007, 13, 32-39.

(2) Dupont, J.; Scholten, J. D. Chem. Soc. Rev. [Online early access]. DOI: $10.1039 / \mathrm{b} 822551 \mathrm{f}$.

(3) Dupont, J.; Fonseca, G. S.; Umpierre, A. P.; Fichtner, P. F. P.; Teixeira, S. R. J. Am. Chem. Soc. 2002, 124, 4228-4229.

(4) Fonseca, G. S.; Machado, G.; Teixeira, S. R.; Fecher, G. H.; Morais, J.; Alves, M. C. M.; Dupont, J. J. Colloid Interface Sci. 2006, 301, 193204.

(5) Wang, Y.; Yang, H. J. Am. Chem. Soc. 2005, 127, 5316-5317.

(6) Dash, P.; Scott, R. W. J. Chem. Commun. 2009, 812-814.

(7) Scheeren, C. W.; Machado, G.; Dupont, J.; Fichtner, P. F. P.; Texeira, S. R. Inorg. Chem. 2003, 42, 4738-4742.

(8) Kramer, J.; Redel, E.; Thomann, R.; Janiak, C. Organometallics 2008, 27, 1976-1978.

(9) Scariot, M.; Silva, D. O.; Scholten, J. D.; Machado, G.; Teixeira, S. R.; Novak, M. A.; Ebeling, G.; Dupont, J. Angew. Chem., Int. Ed. 2008, 47, 9075-9078.
(10) Gelesky, M. A.; Umpierre, A. P.; Machado, G.; Correia, R. R. B.; Magno, W. C.; Morais, J.; Ebeling, G.; Dupont, J. J. Am. Chem. Soc. 2005, $127,4588-4589$.

(11) Torimoto, T.; Okazaki, K.; Kiyama, T.; Hirahara, K.; Tanaka, N.; Kuwabata, S. Appl. Phys. Lett. 2006, 89, 243117.

(12) Wei, G. T.; Yang, Z. S.; Lee, C. Y.; Yang, H. Y.; Wang, C. R. C. J. Am. Chem. Soc. 2004, 126, 5036-5037.

(13) Zhao, D. B.; Fei, Z. F.; Ang, W. H.; Dyson, P. J. Small 2006, 2 , 879-883.

(14) Dupont, J. J. Braz. Chem. Soc. 2004, 15, 341-350.

(15) Neto, B. A. D.; Santos, L. S.; Nachtigall, F. M.; Eberlin, M. N.; Dupont, J. Angew. Chem., Int. Ed. 2006, 45, 7251-7254.

(16) Dupont, J.; Suarez, P. A. Z. Phys. Chem. Chem. Phys. 2006, 8 , $2441-2452$.

(17) Lopes, J.; Padua, A. A. H. J. Phys. Chem. B 2006, 110, 33303335.

(18) Souza, R. F.; Alencar, M.; Meneghetti, M. R.; Dupont, J.; Hickmann, J. M. J. Phys.: Condens. Matter 2008, 20, 155102.

(19) Migowski, P.; Machado, G.; Texeira, S. R.; Alves, M. C. M.; Morais, J.; Traverse, A.; Dupont, J. Phys. Chem. Chem. Phys. 2007, 9, 4814-4821.

(20) Gutel, T.; Santini, C. C.; Philippot, K.; Padua, A.; Pelzer, K.; Chaudret, B.; Chauvin, Y.; Basset, J. M. J. Mater. Chem. 2009, 19, 36243631 .

(21) Redel, E.; Thomann, R.; Janiak, C. Inorg. Chem. 2008, 47, 14-16.

(22) Okazaki, K. I.; Kiyama, T.; Hirahara, K.; Tanaka, N.; Kuwabata, S.; Torimoto, T. Chem. Commun. 2008, 691-693.

(23) Okazaki, K.; Kiyama, T.; Suzuki, T.; Kuwabata, S.; Torimoto, T. Chem. Lett. 2009, 38, 330-331.

(24) Suzuki, T.; Okazaki, K.; Kiyama, T.; Kuwabata, S.; Torimoto, T. Electrochemistry 2009, 77, 636-638.

(25) Tsuda, T.; Kurihara, T.; Hoshino, Y.; Kiyama, T.; Okazaki, K.-i.; Torimoto, T.; Kuwabata, S. Electrochemistry 2009, 77, 693-695.

(26) Hatakeyama, Y.; Okamoto, M.; Torimoto, T.; Kuwabata, S.; Nishikawa, K. J. Phys. Chem. C 2009, 113, 3917-3922.

(27) Lovelock, K. R. J.; Kolbeck, C.; Cremer, T.; Paape, N.; Schulz, P. S.; Wasserscheid, P.; Maier, F.; Steinruck, H. P. J. Phys. Chem. B 2009, $113,2854-2864$

(28) Kolbeck, C.; Cremer, T.; Lovelock, K. R. J.; Paape, N.; Schulz, P. S.; Wasserscheid, P.; Maier, F.; Steinruck, H. P. J. Phys. Chem. B 2009, $113,8682-8688$.

(29) Kolbeck, C.; Killian, M.; Maier, F.; Paape, N.; Wasserscheid, P.; Steinruck, H. P. Langmuir 2008, 24, 9500-9507.

(30) Waring, C.; Bagot, P. A. J.; Slattery, J. M.; Costen, M. L.; McKendrick, K. G. J. Phys. Chem. Lett. 2010, 1, 429-433.

(31) Bhargava, B. L.; Balasubramanian, S. J. Am. Chem. Soc. 2006, $128,10073-10078$.

(32) Rivera-Rubero, S.; Baldelli, S. J. Phys. Chem. B 2006, 110, 47564765.

(33) Aliaga, C.; Santos, C. S.; Baldelli, S. Phys. Chem. Chem. Phys. 2007, 9, 3683-3700.

(34) Caporali, S.; Bardi, U.; Lavacchi, A. J. Electron Spectrosc. Relat. Phenom. 2006, 151, 4-8.

(35) Krischok, S.; Eremtchenko, M.; Himmerlich, M.; Lorenz, P.; Uhlig, J.; Neumann, A.; Ottking, R.; Beenken, W. J. D.; Hofft, O.; Bahr, S.; Kempter, V.; Schaefer, J. A. J. Phys. Chem. B 2007, 111, 4801-4806.

(36) Suarez, P. A. Z.; Dullius, J. E. L.; Einloft, S.; DeSouza, R. F.; Dupont, J. Polyhedron 1996, 15, 1217-1219.

(37) Cassol, C. C.; Ebeling, G.; Ferrera, B.; Dupont, J. Adv. Synth. Catal. 2006, 348, 243-248.

(38) Mulvaney, P. Langmuir 1996, 12, 788-800.

(39) Redel, E.; Thomann, R.; Janiak, C. Chem. Commun. 2008, 17891791.

(40) Migowski, P.; Zanchet, D.; Machado, G.; Gelesky, M. A.; Teixeira, S. R.; Dupont, J. Phys. Chem. Chem. Phys. [Online early access]. DOI: 10.1039/B925834E

(41) Liu, Q.-S.; Tong, J.; Tan, Z.-C.; Welz-Biermann, U.; Yang, J.-Z.

J. Chem. Eng. Data [Online early access]. DOI:021/je901035d.

(42) Lynden-Bell, R. M.; Del Popolo, M. Phys. Chem. Chem. Phys. 2006, 8, 949-954.

(43) Lockett, V.; Sedev, R.; Bassell, C.; Ralston, J. Phys. Chem. Chem. Phys. 2008, 10, 1330-1335.

(44) Santos, C. S.; Baldelli, S. J. Phys. Chem. B 2009, 113, 923-933.

(45) Umpierre, A. P.; Machado, G.; Fecher, G. H.; Morais, J.; Dupont, J. Adv. Synth. Catal. 2005, 347, 1404-1412.

(46) Moreno-Manas, M.; Pleixats, R.; Tristany, M. J. Fluorine Chem. 2005, 126, 1435-1438.

(47) Tristany, M.; Chaudret, B.; Dieudonne, P.; Guari, Y.; Lecante, P.; Matsura, V.; Moreno-Manas, M.; Philippot, K.; Pleixats, R. Adv. Funct. Mat. 2006, 16, 2008-2015.

JP102231X 